\title{
Supranucleosomal and Non-Nucleosomal Chromatin Configurations
}

\author{
W.W. FRANKE, H. ZENTGRAF, U. SCHEER
}

A significant contribution to the understanding of chromatin organization was the discovery of the nucleosome as a globular repeating unit of the package of DNA (Hewish and Burgoyne, 1973; Woodcock, 1973; Kornberg, 1974; Olins and Olins, 1974; for review see Oudet et a1., 1978a). In accord with the original definition and in agreement with most workers in this field of research we identify a nucleosome as a spherical or slightly oblate granular particle $10-13 \mathrm{~nm}$ in diameter, containing about 200 base pairs of DNA and two of each of the four histones $\mathrm{H} 2 \mathrm{a}, \mathrm{H} 2 \mathrm{~b}, \mathrm{H} 3$ and $\mathrm{H} 4$. It is this structure in which the bulk of the nuclear chromatin is organized in most eukaryotic cells, with the exception of the dinoflagellates (Rae and Steele, 1977; dinoflagellate DNA, however, can be packed into nucleosomal structures in vitro by addition of the appropriate amounts of histones; the same reference). Although it seems clear from the work reported that condensed and transcriptionally inactive chromatin is contained in nucleosomes as the principle for first order packing of DNA there are two important questions onto which we are focusing in the present study: (i) What is the higher order of packing present in - and perhaps typical of - the condensed state of chromatin, and (ii) what is the specific form of arrangement of transcriptionally active chromatin?

\section{Supranucleosomal Organization}

It is long known that condensed chromatin inactive in transcription is different in morphology from the more dispersed form of chromatin which is assumed to contain regions actively engaged in transcription. For example, the highly condensed chromatin in spermatids and many forms of sperm cells, late stages of erythropoesis, nuclear pyknosis, peripheral blocks of heterochromatin, including pericentrometric and/or telomeric portions, appears in ultrathin sections as very densely packed, intensely stained granular units (for discussion and references see Franke and Scheer, 1974; Franke et al., 1978). In many interphase nuclei, the chromatin enriched in the $18-26 \mathrm{~nm}$ granules is localized in the layer 


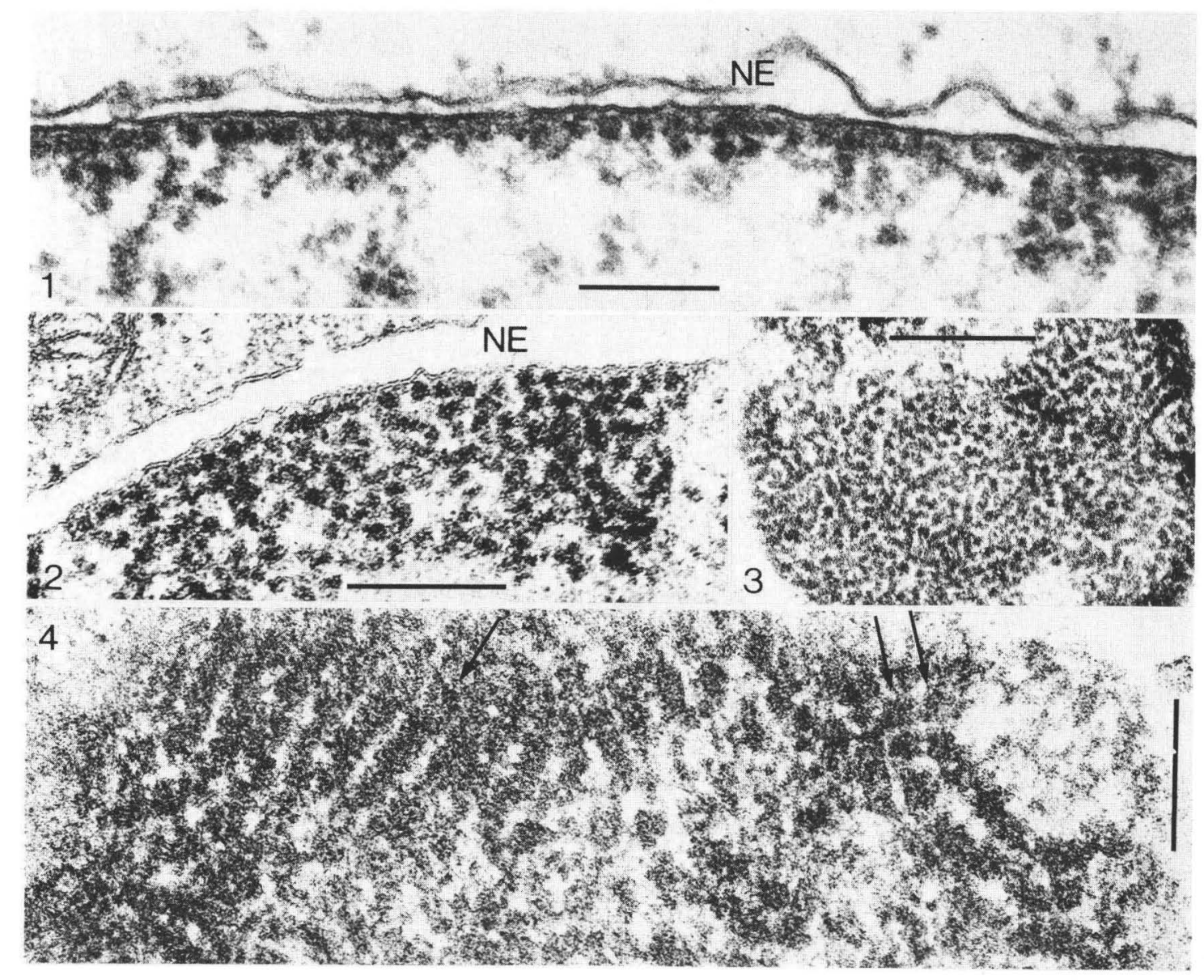

Figures 1-4. Large granules are seen in peripheral condensed chromatin of a murine 3 T 3 cel1 (1) and late stages of hen erythroblasts (2-4). Note rows (arrows in 4) of tightly juxtaposed granules, seen in crosssections (2) and grazing sections $(3,4)$ of the nucleus (NE, nuclear envelope). Scales denote 0.2 , um $(1,2), 0.3$, um (3), and 0.1 , um (4).

Figures 5-9. Nucleosomal (6-8) and supranucleosomal (5,6,9) granular packing of chromatin as seen in spread preparations of peripheral, nuclear envelope-associated (5), and "free" (e.g., 6,7) chromatin from cultured murine sarcoma 180 cells (5-7; for details see Franke et al., 1976a). Note the rows of large supranucleosomal granules present in the layer immediately underneath the nuclear envelope (5). Figures 6 and 7 show the simultaneous occurrence of both compact supranucleosomal granules (in the left of 6) and extended nucleosomal chains (nucleofilaments, 6 and, at higher magnification, 7); the latter conformation is predominant after prolonged exposure to low salt buffers. Figures 8 and 9 show the nucleosomal (8) and supranucleosomal (9) form of packing of the circular SV 40 DNA molecule which is included here for direct comparison (for details and references see text and Zentgraf et al., 1978). Scales denote 0.5 , um $(5,6)$ and 0.2 , um $(7-9)$. 
$+x^{2}, *$

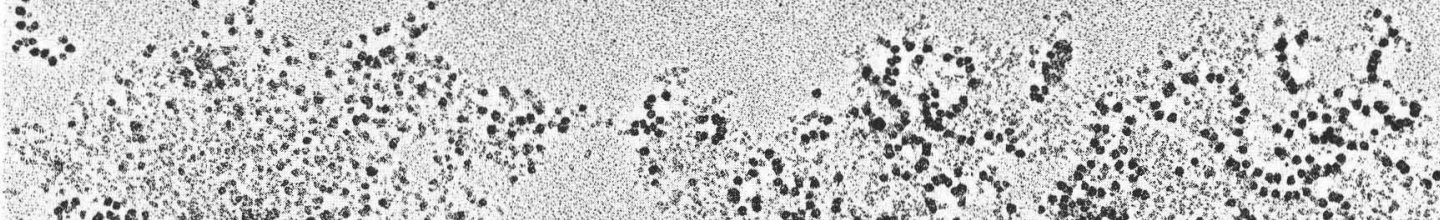

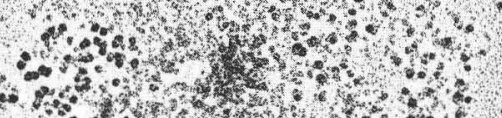

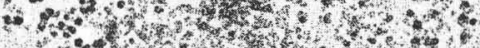

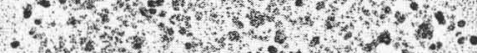

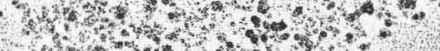

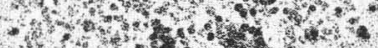

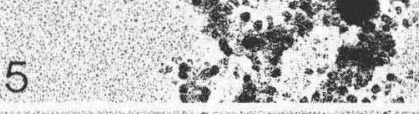

*t.

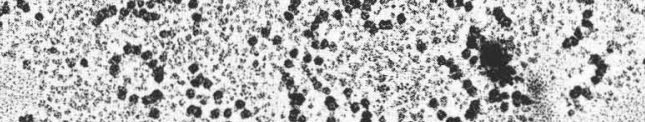

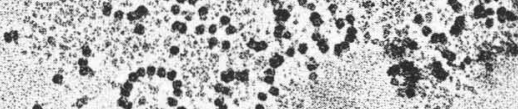

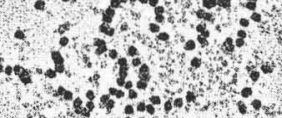

6

$5, x_{i}$

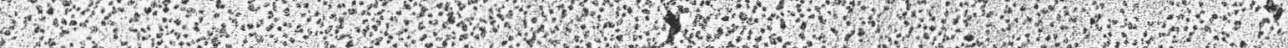

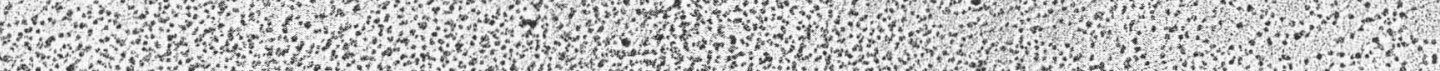
W P.

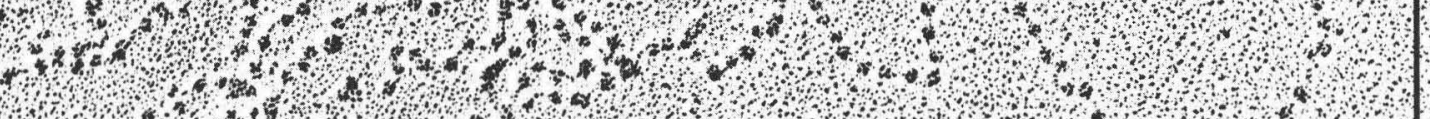

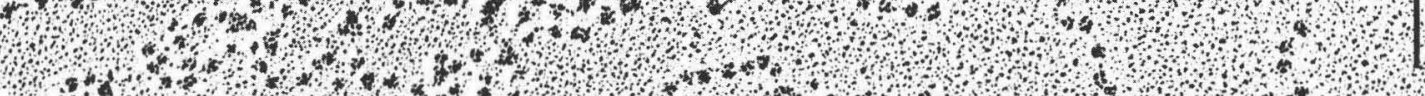

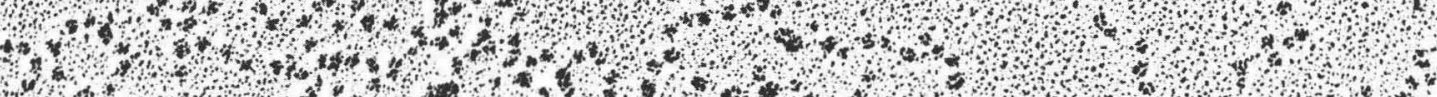

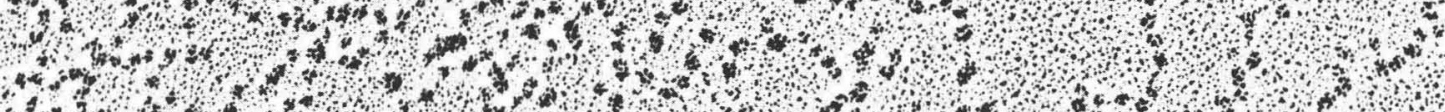

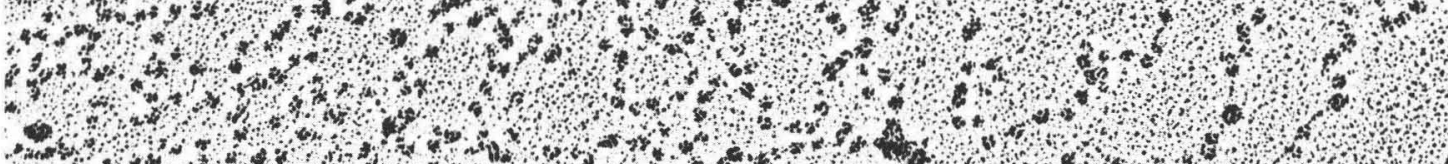

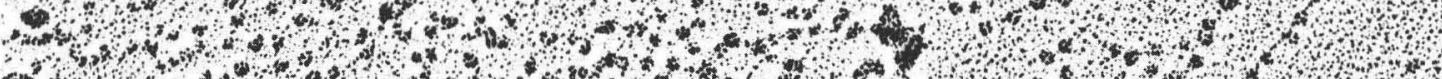

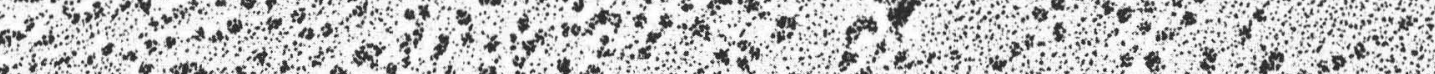

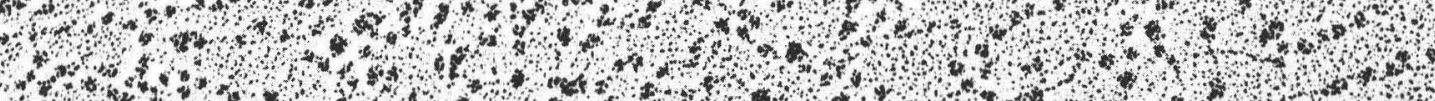

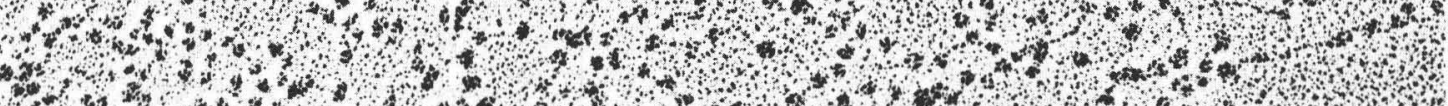

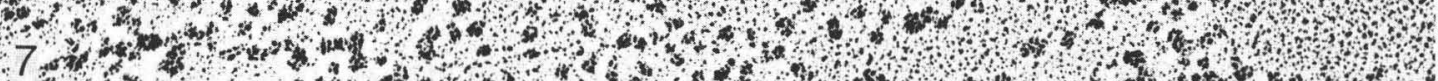

immediately underneath the inner nuclear membrane (Figs. 1 and 2). When examined in grazing nuclear sections this chromatin fraction appears organized in rows of tightly juxtaposed beads (Figs. 3 and 4; Zentraf et a1., 1975, Franke and Scheer, 1974; as to interpretations of such "cords" as continuous cylinders see Davies and Haynes, 1975). When nuclei are disrupted and exposed to buffer solutions of low ionic strength, a progressive unravelling and dispersal of the dense chromatin into nucleofilaments (for definition see Klug, 1978) is observed. It is this type of preparation that originally has led to the discovery of the presence of nucleosomes in chromatin (for references see above). However, after brief exposures to media of very low ionic strength or to moderately elevated (ca. 1-10 mM alkali) salt a relatively large proportion of the chromatin is recognized in form of the large supranucleosomal granules (Fig. 5); large granules and normal nucleofilament strands occur simultaneously (Figs. 6 and 7). This type of 18-30 nm large "beads-on-astring" arrays is especially frequent in spread preparations of the nuclear envelope-associated chromatin, in conformity with the observed relatively high resistance of this peripheral condensed chromatin to solubilization and dispersion (cf. Franke, 1974; Franke and Scheer, 1974; Franke et a1., 1976a). Similar large granules have been observed in chromatin preparations from various cell types (e.g., Kiryanov et a1., 1976; Renz et a1., 1977; Hozier et a1., 1977; Strätling et al., 1978) and are also characteristic of the SV4O chromatin prepared under nearly physiological salt conditions (Zentgraf et al., 1978; Keller et al., 1978; Müller et a1., 1978; see also Griffith, 1975; Griffith and Christiansen, 1978; Varshavsky et a1., 1977, 1978). Detailed analysis of the packing of the SV4O genome has shown that this circular DNA molecule is packed at the first order level into approximately 26 nucleosomes, corresponding to a foreshortening ratio of the DNA of about 5.5:1 (Fig.8). This extended nucleofilament state can be observed in preparations exposed to very low salt concentrations and after removal of histone H1. The extended nucleofilament can be readily brought back in physiological salt concentrations to the large supranucleosomal granular form as long as histone $\mathrm{H} 1$ is present; depletion of histone $\mathrm{H} 1$ results in an irreversible unfolding (e.g., Griffith and Christiansen, 1978; Keller et al., 1978; Mü11er et a1., 1978; cf. Renz et al., 1977). Packing into large granules has also been described for rat liver chromatin after limited digestion with micrococcal nuclease in the form of monomeric, dimeric and oligomeric spherical units, with each unit containing eight nucleosomes (Strätling et al., 1978). The supranucleosomal packing therefore results in a total DNA foreshortening of about twentyfold. As a result the SV40 genome, for example, is condensed into a compact aggregate of an average of four (3-5) supranucleosomal large beads (Fig. 9). The $25 \mathrm{~nm}$ thick chromatin fibrils described by Thoma and Koller (1977) in histone H1-containing chromatin also reveal occasional large granules of the type described here. The concept of a granular form of supranucleosomal package is in apparent contrast to solenoidal models as proposed by Klug and coworkers (e.g., Finch and Klug, 1976; Klug, 1978) and by Worcel and Benyajati (1977); this discrepancy might be explained, however, by differences in the preparation of the chromatin samples.

\section{Morphology of Actively Transcribed Chromatin}

The definition of transcriptionally active chromatin is usually a difficult one. In most situations in which a specific gene or chromatin region is assumed to be active in transcription the relative extent and rate of transcription still remains unclear. Low frequency of transcriptional events, i.e. low packing density of transcriptional complexes along the chromatin fibril, allows the classification of two categories of chromatin within the specific transcriptional unit, (i) transcriptionally active intercepts and (ii) regions not transcribed at the moment of isolation (see below). Therefore, in studying the morphology of transcriptionally active chromatin it seems advantageous to first study 
the extreme, namely chromatin containing the full complement of transcriptional complexes. Examples of such structures are represented by the nuclear genes coding for the common precursors (pre-rRNA) to $28 \mathrm{~S}$, $18 \mathrm{~S}$ and $5.8 \mathrm{~S}$ rRNAs ( $\mathrm{S}$ values are only nominal as used for classification) during stages of maximal transcription, lampbrush chromosome loops, and probably also puffs of polytene chromosomes.

Nucleolar Chromatin

When examined in ultrathin sections actively transcribed nucleolar chromatin appears as very dispersed strands embedded in massive accumulations of associated nascent ribonucleoprotein (RNP) material; large beads of the type described above in condensed chromatin are not recognized (cf. Franke et a1., 1978).

In electron micrographs of spread preparations (Miller and Beatty, 1969) of fully transcribed chromosomal or extrachromosomal nucleoli the genes coding for pre-rRNA are usually identified in characteristic arrays of tandemly arranged matrix units (for palindromic arrangements see also Gall et al., 1977; Grainger and Ogle, 1978; cf. also Berger et a1., 1978) densely covered by lateral RNP fibrils. These matrix units are separated by apparent spacer regions that are free of - or are only irregularly or sparsely populated by - RNA polymerase particles and transcriptional complexes (for detailed discussion see Franke et al., 1976b). Typical arrangements of transcriptional units and spacer regions are shown in Figures 11 and 12. Within the matrix units the lateral fibrils increase gradually. However, in several types of rDNA transcriptional units, especially the long ones observed in certain insects (Trendelenburg et al., 1973, 1976, 1977) and mammals (Miller and Bakken, 1972; Puvion-Dutilleul et al., 1977 a,b), no further increase in fibril lengths was found in the second half of the matrix units. Intensely stained, granular particles 10-14 $\mathrm{nm}$ in diameter are usually observed at the bases of the lateral fibrils. These are considered to represent the RNA polymerase A complexes engaged in elongation of the specific attached RNP fibril. In maximally active matrix units these basal granules are closely packed and would not leave space for additional nucleosomes, nor have additional nucleosomes been observed in such regions. Moreover, "gaps" of thin thread-1ike strands interspersed between the transcriptional complexes, equivalent to unfolded nucleosomes, do likewise not occur in fully covered transcriptional units. Another argument against a significant foreshortening of the transcribed DNA is the correspondence of the length of the pre-rRNA molecules identified and the mean length of the matrix units as it has been measured in many, though not in al1, organisms (for references see Franke et al., 1976b, 1978). That DNA of both spacer regions and transcriptional units is not condensed but rather extended is also indicated by the correspondence, within the same species, of the repeat unit lengths, i.e. matrix unit plus adjacent spacer intercept, to the repeat unit lengths determined in the isolated rDNA by digestion with restriction endonucleases (Franke et a1., 1976a; Scheer et a1., 1977; Wellauer et al., 1974, 1976). The same correspondence of lengths has been found in the circular amplified rDNA molecules in the oocytes of the insects, Dytiscus and Acheta (Trendelenburg et al., 1976). In matrix units not fully covered with transcriptional complexes one observes fibril-free intercepts of variable sizes, i.e. regions momentarily not engaged in transcription but relative close, by time and space, to adjacent transcriptional events (see Figs. 12 and 13; cf. Meyer and Hennig, 1974; Scheer et al., 1975, 1976a; Scheer, 1978). Again these regions appear as thin (4-8 nm) and uniform chromatin strands and do not show particles of nucleosomal size (cf. Franke et al., 1976a). The perhaps most compelling evidence for the absence of nucleosomal structures in matrix units is the demonstration of the preservation of the essential structural features described above after removal of most of the chromatin proteins, in particular the histones, with the detergent Sarkosyl under conditions which leave the transcriptional complexes still 
identifiable (Franke et a1., 1976a; Scheer et al., 1977; Scheer, 1978). This absence of nucleosomes in matrix unit regions has also been observed by Foe, Wilkinson and Laird (1976). In addition, Foe (1978) has shown that during activation of nucleolar transcription in the embryogenesis of Oncopeltus a structural change can be observed in nucleolar chromatin, namely regions corresponding to matrix intercepts can be identified as being free of nucleosomes ("smooth") before synthesis of prerRNA commences. This indicates the existence of an intermediate state of chromatin conformation in which nucleosomal structure appears to be unfolded but transcription has not yet been initiated.

Various authors have described the presence of granular particles of about 10-14 nm in diameter in apparent spacer regions and have concluded that they represent nucleosomes resulting in a selective foreshortening of the spacer DNA (e.g., Foe et al., 1976; Woodcock et al., 1976; Grainger and Ogle, 1978). Our observations namely, that the number of such spacer-associated particles is not correlated with the mean spacer length (Franke et al., 1976a) and that the spacer lengths are not significantly increased upon removal of most of the proteins, especially the histones, with Sarkosyl (Scheer et a1., 1977) argues against this interpretation. On the other hand, it has been shown that at least some spacer-associated particles of this size class are preserved after such treatment, i.e. a behaviour similar to that of transcriptional complexes (Franke et a1., 1976a; Scheer et a1., 1977; Scheer, 1978). These and other findings which are in correspondence to the occasional occurrence of transcriptional complexes with nascent RNP fibrils in apparent spacer regions (Scheer et a1., 1973, 1977; Franke et a1., 1976a; Franke and Scheer, 1978; Franke et a1., 1978) tend to indicate that neither the matrix units nor the spacer regions of transcriptionally active nucleolar chromatin are arranged in nucleosomal package but are rather extended DNP fibrils.

Non-Nucleolar Chromatin

Electron microscopic studies on the chromatin of fully transcribed non-nucleolar transcriptional units are relatively sparse. High density of transcriptional complexes has been observed in the loops of lampbrush chromosomes (Figs. 14 and 15; Scheer et a1., 1976b; see there for further references), in the putative transcriptional unit of the silk fibroin gene in the silk glands of Bombyx mori (McKnight et al., 1976) and may also be present in heavily transcribed puffs such as the Balbiani ring II of Chironomus salivary glands. Detailed studies of the organization of 1 ampbrush chromosome loops have shown that loops relatively densely covered with transcriptional complexes usually are thin and "smooth", i.e., no nucleosome-sized granules are recognized (Figs. 14 and 15; Franke et a1., 1976a; Scheer et a1., 1976b). The same nonbeaded aspect is usually observed in regions adjacent to such non-nucleolar, often very long transcriptional units that seem to represent spacer regions not simultaneously transcribed (same refs). In this connection, however, it is worth emphasizing that most situations of transcription of genes coding for messenger RNAs are not characterized by a similar high density of transcriptional complexes as observed in lampbrush chromosome loops and polytene chromosome puffs. Rather distant transcriptional complexes have been described in spread preparations of rat liver chromatin (e.g., Franke, 1977) and chromatin from various other "normal" interphase cells (Miller and Bakken, 1972; Foe et al., 1976; Laird and Choii, 1976; Laird et a1., 1976; Puvion-Dutilleul et a1., 1977a). Therefore, these situations seem to reflect rather complex transcriptional units in which relatively short active regions are separated by relatively extended inactive ones (see below). 







\section{Structural Changes During Inactivation of Transcription}

The electron microscopic demonstration of highly transcribed genes on the one hand and totally inactive, condensed chromatin on the other hand would suggest that during activation as well as during inactivation of chromatin regions, structural changes take place. As already menttioned, Foe (1978) has described a transition from nucleosomal packing of rDNA-containing chromatin to an extended smooth DNP fibril preceding the onset of rDNA transcription in Oncopeltus embryogenesis. On the other hand, the structural changes of the extrachromosomal nucleolar chromatin present in amphibian oocytes were studied in our laboratory. These ultrastructural changes were most prominent during activation, in early oocegensis, and inactivation, during oocyte maturation or after treatment with transcripitinal inhibitors (Scheer et a1., 1975, 1976; Scheer, 1978). Stages of greatly reduced transcriptional activity of nucleoli are characterized by the appearance of progressively increasing portions of nucleolar chromatin free of lateral RNP fibrils and their corresponding polymerase particles. Concomitantly nucleosomes appear on the previously chromatin (Figs. 16 and 17). The nucleosomal nature of these beaded structures in the regions of nucleolar chromatin has been demonstrated by their unravelling and extension during treatment with Sarkosyl (Scheer, 1978). From these studies it can be concluded that nucleolar chromatin when inactivated assumes a nucleosomal configuration indistinguishable from that described in other sorts of inactive chromatin (cf. Franke et a1., 1976a). In addition, indications of nucleosomal packing have also been observed for inactivated nucleolar chromatin of rDNA circles of Dytiscus oocytes (Scheer, unpublished observations).

Similarly, the inactivation of lampbrush chromosome loops can be studied in oocytes as a model for the structural changes occurring during inactivation of non-nucleolar genes. Loops that are greatly reduced in transcriptional activity are charaterized by sparse lateral RNP fibrils, distant from each other, with long interspersed fibrilfree regions momentarily not engaged in transcription (Franke et al., 1976a; Scheer. 1978). These inactive regions within transcribed loops frequently show a nucleosomal appearance. The nucleosomal nature of the particles observed during inactivation has been demostrated by their selective removal by treatment with Sarkosyl (Scheer, 1978). Similar nucleosome-like granules have been described in spread preparations of sparsely fibril-covered non-nucleolar chromatin of various other sources (Foe et a1., 1976; Laird et al., 1976; Laird and Choii, 1976; McKnight et a1., 1978).

\section{Concluding Remarks}

Our observations suggest that transcriptionally inactive chromatin is organized differently from transcribed chromatin regions. This conclusion is supported by a series of biochemical data (e.g., Gottesfeld et a1., 1975; Gare1 and Axe1, 1976; Weintraub and Groudine, 1976; Bellard et al., 1978; see there for further references). Specifically

Figures 10-13. Transcriptional units and apparent spacer regions of transcripionally active nucleolar chromatin of oocytes of the newts, Pleurodeles waltli (10), Triturus cristatus (11), and Triturus alpestris $(12,13)$. Note the dense coverage with transcriptional complexes in the matrix units of Figs. 10 and 11 (from mid-oogenesis) compared to the somewhat reduced lateral fibril density of the less active matrix unit shown in Fig. 13 (matrix units shown in Figs. 12 and 13 are from maturing oocytes). Note thin spacer fibrils (the preparation shown in Fig.12 has been treated with $0.4 \%$ Sarkosyl); for details see text. Scales denote 1 , um $(10,11)$ and 0.5 , um $(12,13)$. 


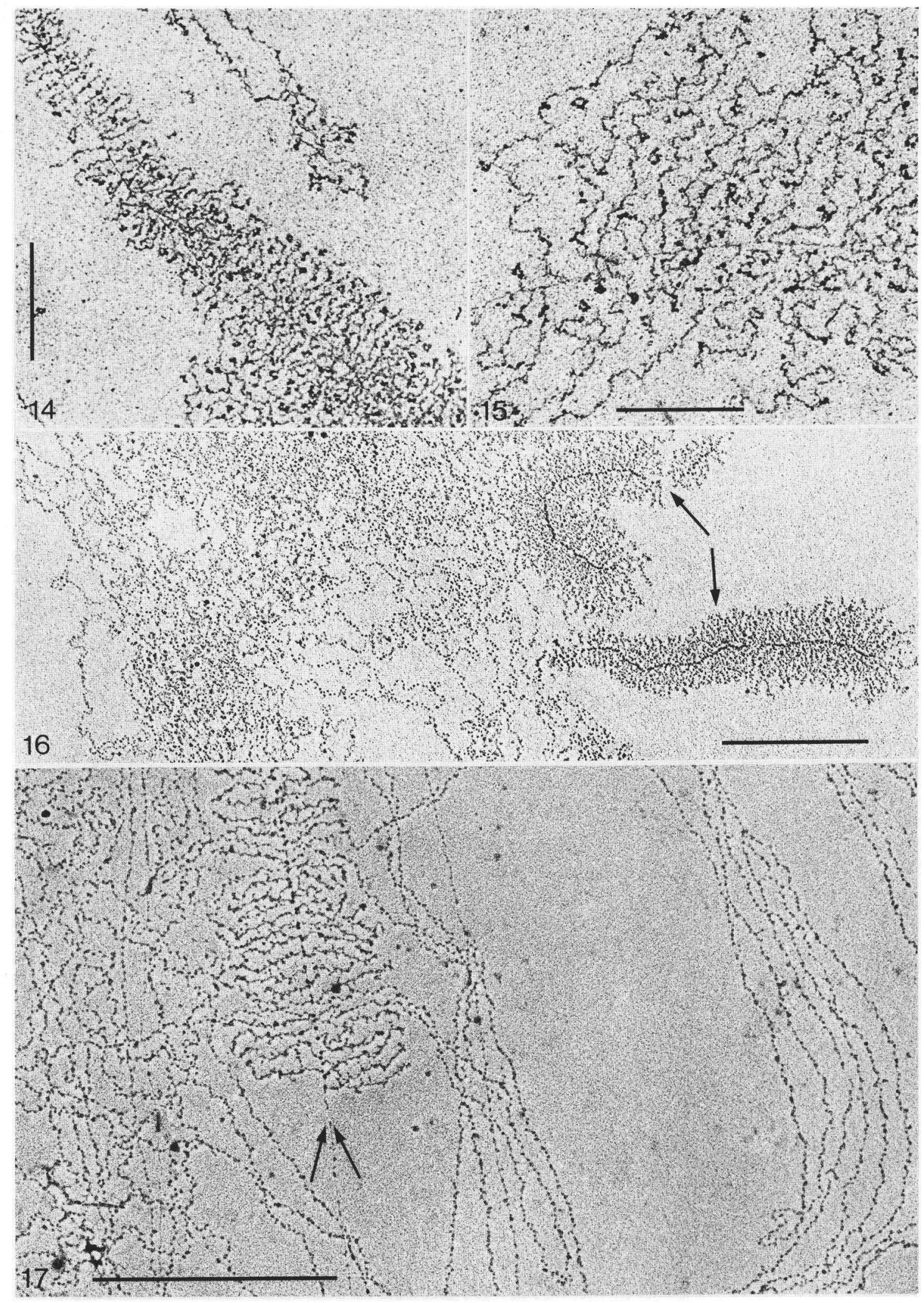


our findings tend to indicate that the transcriptionally inactive chromatin is condensed into nucleosomes, in the first order, and into larger supranucleosomal granules at the higher level of organization. On the other hand, in transcribed regions of chromatin the DNA is not significantly foreshortened and appears in the form of an extended, relatively thin (4-8 nm) DNP fibril. Transitions between both stages of organization have been observed but the mechanisms involved in such alterations and the transition times are not known. Our observations in lampbrush chromosome loops of greatly reduced transcriptional activity suggest that, at least in this type of non-nucleolar chromatin, such changes can take place within relatively short periods of time, i.e. within seconds or a few minutes, after a specific transcriptional event (Scheer, 1978).

Our concept that the transcriptionally active chromatin regions are not compacted in nucleosomal units at first sight seems to be in conflict with data and conclusions reported by several authors from biochemical experiments (e.g., Mathis and Gorovsky, 1976; Piper et al., 1976; Reeves, 1976 and 1977; Reeves and Jones, 1976; Gottesfeld and Me1ton, 1978; for further references see Franke et al.,1978, and Scheer, 1978). These authors have found that DNA sequences of genes that are knwon or assumed - to be transcribed are contained in nucleosome-sized fragments as obtained by digestion of chromatin with micrococcal nuclease. However, the finding that a specific DNA sequence is recovered in such 140-200 base pair fragments cannot be interpreted as evidence for its presence in nucleosomal packing in the native chromatin (for definition of nucleosomes see the introductory remarks) since it has been shown that such fragments are also obtained when unfolded, i.e. non-nucleosomal chromatin is treated with this enzyme (Jackson and Chalkley, 1975; see also Oudet et a1., 1978b, and Woodcock and Frado, 1978). Consequent1y, such digestion experiments do not allow the distinction of the condensed nucleosomal form from the extended state of the nucleohistone complex but rather demonstrate the regular pattern of association of nucleosomal histones with the DNA molecule. In this connection it is perhaps also worth emphasizing that our concept of a non-nucleosomal organization of transcribed chromatin does not imply the absence of histones in such regions. There is some evidence that histones are present in transcriptionally active chromatin (e.g., McKnight et al., 1978), including nucleolar chromatin (Higashinakagawa et a1., 1977) and lampbrush chromosome loops (Scheer and Sperling, unpublished observations) of amphibian oocytes. What we hypothesize is the existence of a DNP arrangement different from the condensed nucleosomal form and that this non-nucleosomal form occurs in transcribed chromatin. The specific molecular architecture of this arrangement remains to be elucidated.

Figures 14 and 15 . Two regions of the same transcriptional unit of a lampbrush chromosomee loop of a mid-vitellogenic Alpine newt, showing high density of trancriptional complexes with relatively short lateral fibrils in the start region (14) and with long lateral fibrils in more distal portions of the unit (15). Note thin DNP axis of the loop. Scales denote 1 , um.

Figures 16 and 17. Simultaneous occurrence of both forms of chromatin, nucleosomal "beads-on-the-string" in regions free of lateral fibrils and thin, smooth DNP fibrils containing extended DNA in transcribed regions, seen in nucleolar chromatin of newt oocytes (T. alpestris) that has been greatly inactivated during treatment with actinomycin $D$ (16; cf. Scheer et al., 1975) or during natural oocyte maturation (17; cf. Scheer, 1978). The two arrows in Fig 17 denote the transcriptionally active strand, those in Fig. 16 indicate the two actively transcribed genes among inactive chromatin strands. Scales represent 1 um. 


\section{References}

Bellard, M., Gannon, F., and Chambon, P. Nucleosome structure.III. Are actively transcribed genes compacted in nucleosomes? Cold Spring Harbor Symp. Quant. Bio1. 42: in press, 1978.

Berger, S., Zeilmer, D.M., Kloppstech, K., Richter, G., Dillard, W.L., and Schweiger, H.G. Alternating polarity in rRNA genes. Cell Biol. Int. Rep. 2:41-50, 1978 .

Davies, H.G., and Haynes, M.E. Light- and electron microscope observations on certain leukocytes in a teleost fish and a comparison of the envelope-limited monolayers of chromatin structural units in different species. J. Ce11 Sci. 17: 263-285, 1975 .

Finch, J.T., and Klug, A. Solenoidal model for superstructure in chromatin. Proc. Nat. Acad. Sci. USA 73:1897-1901, 1976.

Foe, V.E. Chromatin structure and transcriptional activity: an electron microscopic study of rRNA synthesis. Cold Spring Harbor Symp. Quant. Biol. 42: in press, 1978 .

Foe, V.E., Wilkinson, L.E., and Laird, C.D. Comparative organization of active transcription units in Oncopeltus fasciatus. Cel1 9:131-146, 1976 .

Franke, W.W. Structure, biochemistry, and function of the nuclear envelope. Int. Rev. Cyto1. Supp1. 4:71-236, 1974.

Franke, W.W. Genexpression der Eukaryontenzelle und Prinzipien ihrer Regulation. Arzneim.-Forsch./Drug Res. 27:190-199, 1977.

Franke, W.W., and Scheer, U. Structures and functions of the nuclear envelope. In: The Cell Nucleus. Vo1. 1, p. 219-347 (ed. H. Busch), Academic Press, New York, 1974.

Franke, W.W., and Scheer, U. Morphology of transcriptional units at different states of activity. Phil. Transc. Roy. Soc. Lond. B 283 : $333-342,1978$.

Franke, W.W., Scheer, U., Trendelenburg, M.F., Spring, H., Zentgraf, H. Absence of nucleosomes in transcriptionally active chromatin. Cytobiol. $13: 401-434,1976 \mathrm{a}$.

Franke, W.W., Scheer, U., Spring, H. Trendelenburg, M.F., and Krohne, G. Morphology of transcriptionaliy units of rDNA. Exp. Cell Res. 100: $233-244,1976 \mathrm{~b}$.

Franke, W.W., Scheer, U., Trendelenburg, M.F., Zentgraf, H., and Spring, H. Morphology of transcriptionally active chromatin. Cold Spring Harbor Symp. Quant. Biol. 42: in press, 1978.

Gall, J.G., Karrer, K., Yao., M.C., and Grainger, R. The ribosomal RNA genes in Tetrahymena. In: The Organization and Expression of the Eukaryotic Genome. 437-444. E.M. Bradbury and K. Javaherian, eds., Academic Press, New York, 1977.

Gare1, A., and Axel, R. Selective digestion of transcriptionally active ovalbumin genes from oviduct nuclei. Proc. Nat. Acad. Sci. USA 73: 3966-3970, 1976 .

Gottesfeld, J.M., Murphy, R.F., and Bonner, J. Structure of transcriptionally active chromatin. Proc. Nat. Acad. Sci. USA 72:4404-4408, 1975.

Gottesfeld, J.M., and Melton, D.A. The length of nucleosome-associated DNA is the same in both transcribed and nontranscribed regions of chromatin. Nature 273:317-319, 1978 .

Grainger, R.M., and Ogle, R.C. Chromatin structure of the ribosomal genes in Physarum polycephalum. Chromosoma 65:115-126, 1978 .

Griffith, J.D. Chromatin structure: deduced from a minichromosome. Science 187:1202-1203, 1975 .

Griffith, J.D., and Christiansen G. The multifunctional role of histone H1: probed with the SV 40 minichromosome. Cold Spring Harbor Symp. Quant. Biol. 42: in press, 1978.

Hewish, D.R. and Burgoyne, L.A. Chromatin substructure. The digestion of chromatin DNA at regularly spaced sites by a nuclear deoxyribonuclease. Biochem. Biophys. Res. Com. 52:504-510, 1973.

Higashinakagawa, T., Wahn, H., and Reeder, R.H. Isolation of ribosomal gene chromatin. Dev. Bio1. 55:375-386, 1977 . 
Hozier,J.,Renz,M., and Nehls,P. The chromosome fiber: evidence for an ordered superstructure of nucleosomes. Chromosoma 62:301-317,1977.

Jackson, V., and Chalkley, R. The effect of urea on staphylococcal digestion of chromatin. Biochem. Biophys. Res. Com. 67: 1391-1400,1975.

Keller,W. ,Müller,U.,Eicken,I.,Wende1, I., and Zentgraf,H. Studies on SV 40 chromatin. Cold Spring Harbor Symp. Quant. Biol. 42:in press, 1978 .

Kiryanov,G.I., Manamshjan,T.A., Polyakov, V.Ju.,Fais,D., and Chentsov, Ju. Levels of granular organisation of chromatin fibers. FEBS letters $67: 323-327,1976$.

Klug,A. Structure of chromatin. Phi1. Trans. Roy. Soc. Lond. B 283: 233239,1978 .

Kornberg,R.D. Chromatin structure: a repeating unit of histones and DNA. Science 184: 868-871,1974.

Laird,C.D., and Chooi,W.Y. Morphology of transcription units in Drosophila melanogaster. Chromosoma 58: 193-218,1976.

Laird,C.D., Wilkinson,L.E., Foe,V.E., and Chooi,W.Y. Analysis of chromatin-associated fiber arrays. Chromosoma 58: 169-192,1976.

Mathis,D.J., and Gorovsky,M.A. Subunit structure of rDNA-containing chromatin. Biochemistry 15: 750-755,1976.

McKnight,S.L., Sullivan,N.L., and Miller,O.L. Visualization of the silk fibroin transcription unit and nascent silk fibroin molecules on polyribosomes of Bombyx mori. Progr. Nucleic Acid Res. and Mol. Biol. 19: 313-318, 1976 .

McKnight,S.L., Bustin,M., and Miller,O.L. Electron microscopic analysis of chromosome metabolism in the Drosophila melanogaster embryo. Cold Spring Harbor Symp. Quant. Biol. 42: in press,1978.

Meyer,G.F., and Hennig,W. The nucleolus in primary spermatocytes of Drosophila hydei. Chromosoma 46: 121-144,1974.

Miller,O.L., and Beatty, B.R. Visualization of nucleolar genes. Science $164: 955-957,1969$.

Miller,O.L., and Bakken,A.H. Morphological studies of transcription. Acta endocrino1. supp1. 168: 155-177,1972.

Müller,U., Zentgraf,H.,Eicken,I., and Keller,W. Higher order structure of the simian virus 40 chromatin. Science, in press, 1978 .

Olins,A.L., and Olins,D.E. Spheroid chromatin units (v bodies). Science 183: $330-332,1974$.

Olins,D.E., Bryan,P.N., Harrington,R.E.,Hi11,W.E., and Olins,A.L. Conformational states of chromatin $v$ bodies induced by urea. Nucleic Acid Res. 4: 1911-1931,1977.

Oudet,P., Germond,J.E., Bellard,M., Spadafora,C., and Chambon,P. Nucleosome structure. Phil. Trans. Roy. Soc. Lond. B 283:241-258,1978a.

Oudet,P., Spadafora,C., and Chambon,P. Nucleosome structure.II.Structure of SV 40 minichromosomes and electron microscopic evidence that a nucleosome could be constituted of two half nucleosomes. Cold Spring Harbor Symp. Quant. Bio1. 42: in press,1978b.

Piper,P.W., Celis,J.,Kaltoft,K., Leer,J.C., Nielsen,O.F., and Westergaard, 0. Tetrahymena ribosomal RNA gene chromatin is digested with micrococcal nuclease at sites which have the same regular spacing on the DNA as corresponding sites in the bulk nuclear chromatin. Nucleic Acids Res. 3: 493-505,1976.

Puvion-Dutilieul,F., Bernadac,A., Puvion,E., and Bernhard,W. Visualization of nuclear transcriptional complexes in rat liver cells. J. U1trastruct. Res. 58: 107-117,1977a.

Puvion-Dutilleul,F., Bachellerie,J.-P., Zalta,J.-P., and Bernhard,W. Morphology of ribosomal RNA transcription units in isolated subnuclear fractions of mammalian cells. Biol. Cellulaire 30: 183-194,1977b.

Rae,P.M.M., and Steele,R.E. Modified bases in the DNAs of unicellular eukaryotes. Biosystems, in press, 1977.

Reeves,R. Ribosomal RNA genes of Xenopus laevis: evidence of nucleosomes in transcriptionally active chromatin. Science 194:529-532,1976.

Reeves,R. Analysis and reconstruction of Xenopus ribosomal chromatin nucleosomes. Europ. J. Biochem. 75: 545-560,1977. 
Reeves,R., and Jones,A. Genomic transcriptional activity and the structure of chromatin. Nature 260: 495-500,1976.

Renz,M., Neh1s,P., and Hozier,J. Involvement of histone H1 in the organization of the chromosome fiber. Proc. Nat. Acad. Sci USA 74:18791883,1977 .

Scheer,U. Changes of nucleosome frequency in nucleolar and non-nucleolar chromatin as a function of transcription: an electron microscopic study. Ce11 13: 535-549,1978.

Scheer,U.,Trendelenburg,M.F., and Franke,W.W. Transcription of ribosomal RNA cistrons. Exp. Cell Res. 80: 175-190,1973.

Scheer,U., Trendelenburg,M.F., and Franke,W.W. Effects of actinomycin D on the association of newly formed ribonucleoproteins with the cistrons of ribosomal RNA in Triturus oocytes. J. Cell Biol.65:163-179, 1975 .

Scheer,U., Trendelenburg,M.F., and Franke,W.W. Regulation of transcription of genes of ribosomal RNA during amphibian oogenesis. J. Cell Biol. 69: 465-489,1976a.

Scheer,U., Franke,W.W.,Trendelenburg,M.F., and Spring,H. Classification of loops of lampbrush chromosomes according to the arrangements of transcriptional complexes. J. Cel1 Sci. 22: 503-520,1976b.

Scheer,U.,Trendelenburg,M.F., Krohne,G., and Franke,W.W. Lengths and patterns of transcriptional units in the amplified nucleoli of oocytes of Xenopus laevis. Chromosoma 60:147-167,1977.

Strätling,W.H., Müller,U., and Zentgraf,H. Supranucleosomal structure of chromatin. Ce11 Biol. Int. Rep., in press,1978.

Thoma,F., and Koller, Th. The influence of histone H1 on chromatin structure. Cel1 12: 101-107,1977.

Trendelenburg,M.F., Scheer,U., and Franke,W.W. Structural organization of the transcription of ribosomal DNA in oocytes of the house cricket. Nature New Biol. 245: 167-170,1973.

Trendelenburg,M.F., Scheer,U., Zentgraf,H., and Franke,W.W. Heterogeneity of spacer lengths in circles of amplified ribosomal DNA of two insect species, Dytiscus marginalis and Acheta domesticus. J. Mo1. Biol. 108: 453-470,1976.

Trendelenburg,M.F., Franke,W.W., and Scheer,U. Frequencies of circular units of nucleolar DNA in oocytes of two insects, Acheta domesticus and Dytiscus marginalis, and changes of nucleolar morphology during oogenesis. Differentiation 7: 133-158,1977.

Varshavsky,A.J., Bakayev,V.V., Bakayeva,T.G.,Chumackov,P.M.,Shmatchenko, V.V., and Georgiev,G.P.On the structure of cellular and viral chromatin. Phil. Trans. Roy. Soc.Lond. B 283: 275-285,1978.

Varshavsky,A.J., Nedospasov,S.A., Shmatchenko,V.V., Bakayev, V.V., Chumackov,P.M., and Georgiev,G.P. Compact form of SV 40 viral minichromosome is resistant to nuclease:possible implications for chromatin. Nucleic Acids Res. 4: 3303-3325,1977.

Weintraub,H., and Groudine,M. Chromosomal subunits in active genes have an altered conformation. Science 193: 848-856,1976.

Wellauer,P.K., Reeder,R.H., Carrol1,D., Brown,D.D., Deutch,A.,Higashinakagawa, T., and Dawid,I.B. Amplified ribosomal DNA from Xenopus 1 aevis has heterogeneous spacer lengths. Proc. Nat. Acad. Sci USA 71: 2823-2827, 1974 .

Wellauer,P.K., Reeder,R.H., Dawid,I.B., and Brown,D.D. The arrangement of length heterogeneity in repeating units of amplified and chromosomal ribosomal DNA from Xenopus laevis. J. Mol. Biol. 105: 487-505, 1976.

Woodcock,C.L.F. Ultrastructure of inactive chromatin. J. Ce11 Biol. 59: $368 \mathrm{a}, 1973$.

Woodcock,C.L.F., Frado,L.L.Y.,Hatch,C.L., and Ricciardie11o,L. Fine structure of active ribosomal genes. Chromosoma 58:33-39,1976.

Woodcock,C.L.F., and Frado,L.L.Y. Ultrastructure of chromatin subunits during unfolding,histone depletion and reconstitution. Cold Spring Harbor Symp. Quant. Biol. 42: in press, 1978. 
Worcel,A., and Benyajati,C. Higher order coling of DNA in chromatin. Ce11 12: 83-100,1977.

Zentgraf,H.,Falk,H., and Franke,W.W. Nuclear membranes and plasma membranes from hen erythrocytes.IV. Characterization of nuclear membraneassociated DNA. Cytobiol. 11:10-29,1975.

Zentgraf,H., Müller,U., and Keller,W. The structure of SV 40 chromatin. Phi1. Trans. Roy. Soc. Lond. B 283: 299-303,1978.

\section{Acknowledgment}

We thank Drs. U. Müller, W. Keller, M.F. Trendelenburg, and H. Spring for valuable discussions and cooperation. We are indebted to Dr. Y. Daskal (Houston, Texas, USA) for reading and correcting the manuscript. The work has been partly supported by the Deutsche Forschungsgemeinschaft. 